Archived version from NCDOCKS Institutional Repository http://libres.uncg.edu/ir/asu/

\title{
Appalachľan
}

B O O N E, N O R T H C A R O L I N A

\section{Moral Distress Of Nurses Surrounding Neonatal Abstinence Syndrome: Application Of A Theoretical Framework}

\author{
By: Amber Welborn MSN, RN
}

\begin{abstract}
Topic: Neonatal nurses who care for infants with symptoms of neonatal abstinence syndrome (NAS) may experience moral distress through conflicting professional ethics. The nurse may find it difficult to simultaneously exemplify beneficence and nonmaleficence. Objective: The purpose of this paper is to explore the moral distress of nurses in the context of infants experiencing symptoms of NAS and apply a new conceptual model to this phenomenon. Understanding how nurses navigate moral dilemmas may provide insight into strategies to better support them to address moral conflict. Methods: Moral distress was explored in the context of nurses who care for infants with symptoms of NAS. A literature review was completed, followed by the application of the model onto the derived themes. Results: The theoretical application resulted in a framework that exemplifies the experience of caring for infants with symptoms of NAS and their families described by many nurses within the literature. If moral distress is not resolved, negative outcomes may be experienced by the nurse, with additional negative outcomes experienced by the family. Conclusion: This theoretical model provided insight into the experience of moral distress surrounding nursing care for infants with symptoms of NAS. Additional research is needed to investigate moral residue and moral resilience in this particular caregiving dynamic.
\end{abstract}

Welborn, A. Moral distress of nurses surrounding neonatal abstinence syndrome: Application of a theoretical framework. Nurs Forum. 2019; 54: 499 - 504. https://doi.org/10.1111/nuf.12362. Publisher version of record available at: https://onlinelibrary.wiley.com/doi/10.1111/nuf.12362 


\title{
Moral distress of nurses surrounding neonatal abstinence syndrome: Application of a theoretical framework
}

\author{
Amber Welborn MSN, RN
}

The University of North Carolina at Greensboro, Greensboro, North Carolina

\section{Correspondence}

Amber Welborn, MSN, RN, the University of North Carolina at Greensboro.

Email: alcrawfo@uncg.edu

\begin{abstract}
Topic: Neonatal nurses who care for infants with symptoms of neonatal abstinence syndrome (NAS) may experience moral distress through conflicting professional ethics. The nurse may find it difficult to simultaneously exemplify beneficence and nonmaleficence.

Objective: The purpose of this paper is to explore the moral distress of nurses in the context of infants experiencing symptoms of NAS and apply a new conceptual model to this phenomenon. Understanding how nurses navigate moral dilemmas may provide insight into strategies to better support them to address moral conflict.

Methods: Moral distress was explored in the context of nurses who care for infants with symptoms of NAS. A literature review was completed, followed by the application of the model onto the derived themes.

Results: The theoretical application resulted in a framework that exemplifies the experience of caring for infants with symptoms of NAS and their families described by many nurses within the literature. If moral distress is not resolved, negative outcomes may be experienced by the nurse, with additional negative outcomes experienced by the family.

Conclusion: This theoretical model provided insight into the experience of moral distress surrounding nursing care for infants with symptoms of NAS. Additional research is needed to investigate moral residue and moral resilience in this particular caregiving dynamic.
\end{abstract}

KEYWORDS

ethics/moral courage, maternal-child health, models/frameworks, professional issues, theory

\section{1 | INTRODUCTION}

Maternal opioid use has risen four-fold since 2000, with similar trends in neonatal abstinence syndrome (NAS). ${ }^{1,2}$ Withdrawal symptoms in the infant, high-pitched crying, including respiratory distress, feeding difficulties, gastrointestinal dysfunction, and potentially seizure activity, occurs in 55\%-94\% of infants exposed to opioids in utero. Symptoms occur when the source of opioids through the placenta is no longer available after birth. ${ }^{3}$ Treatment requires additional observation and interventions from skilled healthcare providers. Infants with moderate to severe symptoms typically stay in the hospital neonatal intensive care unit (NICU) an average 16.9 days, with total annual Medicaid costs of over $\$ 462$ million. ${ }^{4}$

The NAS epidemic affects a broad range of healthcare providers, including neonatologists, and neonatal nurse practitioners, obstetricians, maternal-child nurses, social workers, physical therapists, and pharmacists. However, it is the neonatal intensive care (NICU) nurse who is charged with providing skilled critical care to high-risk infants including the overwhelming comfort needs of infants exhibiting signs of opiate withdrawal. ${ }^{5-9}$ The presentation of physical symptoms of withdrawal is highly individualized with each infant, as it is not uncommon for mothers to use multiple substances including caffeine, 
tobacco, opioids, and nonopioids, which produce nontraditional and/ or synergistic effects in the neonate. ${ }^{6}$ The care needs for infants exhibiting signs of NAS include creating a low stimulation environment, various feeding interventions, and a multitude of ongoing and sometimes simultaneous comfort techniques such as holding, tight swaddling, rocking and swaying. The time, energy, mental, and emotional labor that is required to care for these infants can be overwhelming for NICU nurses. ${ }^{10,11}$ The purpose of this paper is to explore the literature on moral distress of nurses in the context of infants experiencing symptoms of NAS and apply a new conceptual model to this phenomenon.

Further complicating the situation is the complex communication dynamic between the healthcare team and the infant's family. Nurses consistently report families of NAS infants to be the most difficult to work with due to the inconsistency of visitation, defensive attitudes, and lack of disclosure. ${ }^{5,7-9,12,13}$ Often unbeknownst to nurses, mothers may be experiencing a multitude of stressors, anxieties, and fears leading to some of these described behaviors. ${ }^{7,14,15}$ Competing priorities of the nurse to meet the needs of all the patients and families under their care creates an environment ripe for moral distress.

\section{2 | CONCEPTUALIZATION OF MORAL DISTRESS}

Jameton's seminal work beginning in the 1980s defines moral distress as a state of conflicting values without the possibility for preservation of both values following a decision. Powerlessness triggers moral distress when the individual is unable to perform an action perceived as ethical. ${ }^{16,17}$ Initial research found that moral distress in nurses is caused by anything that inhibits the nurse from acting upon her/his moral judgment. ${ }^{17-25}$

The American Nurses Association (ANA) provides a standard of ethical principles to guide the practice of nurses. Beneficence and nonmaleficence are two core principles in the Code of Ethics defining that the nurse's primary commitment is to the patient, whether an individual, family, or larger group (ANA, 2017). The potential for conflict arises when the nurse experiences a situation where two core ethical beliefs are perceived as mutually exclusive. ${ }^{16,18,25-27}$ Although parsimonious, critics question this conceptualization of moral distress as overly broad and call for further clarification on the moral agency, the ability to discern moral judgments, within complex organizations and diverse practice areas. ${ }^{18,20,28,29}$ Additional work by Corley $^{30}$ additional work suggests that potential for moral distress among nurses exists when their values and perceived obligations are mutually exclusive due to the requirements and views of their work environment.

Concerns about less than desirable quality of care resulting from poor availability of staff and support is a predominant theme in the literature describing causes of moral distress. ${ }^{24,31-33}$ The literature thematically supports the idea that the moral saliency of quality of care is aligned with the values of beneficence and nonmaleficence as they directly relate to the well-being of the individual patient. ${ }^{7-9,27}$

\subsection{Antecedents to moral distress}

Antecedents to moral distress include an individual with a defined set of values within an atmosphere of heightened moral responsibility. ${ }^{26,27}$ The individual is aware of potential moral problems and the morally "right" action in a given situation. ${ }^{26}$ Because values are deeply personal with individualized perceptions, moral distress is an experience of the person rather than an experience of the circumstance. $^{25}$ A stressor or confrontation is introduced to the situation to challenge the nurse's values. The uncertainty that follows is also an antecedent for moral distress. ${ }^{16,18,25-27}$

\section{2 | Defining characteristics}

The defining attributes for moral distress include an internal confrontation of a moral/ethical dilemma, within an atmosphere of the inability to act upon the "right" action, often leading to a feeling of powerlessness. ${ }^{16,18,25-27,34}$ Dudzinski ${ }^{27}$ argues that the perception of harm to another is an additional isolating component of moral distress.

\section{3 | Potential outcomes}

Individuals may manifest the characteristics of moral distress through physical, psychological, or behavioral symptoms demonstrated by compassion fatigue and depersonalization. ${ }^{19,20,23,24,26,35,36}$ Prolonged exposure to moral distress increases the risk for long-term and potentially more traumatic consequences ${ }^{34}$ Ultimately, moral injury and desire to leave the profession may occur. ${ }^{19,24,26,30,34,36}$ The timeframe for short-term versus long-term outcomes is highly individual and based upon the individual's intrinsic nature. However, the experience of personal growth through the process of moral deliberation is also a potential outcome. ${ }^{26,37}$

\section{3 | THEORETICAL MODEL}

Barlem and Ramos ${ }^{26}$ created a theoretical model of moral distress underpinned by the work of Jameton ${ }^{17}$ (Figure 1). This comprehensive model provides a map to follow the potential paths of individuals in an environment where moral issues may arise. Consideration of the potential paths illuminates the potential experiences of individuals, highlighting how the various routes produce altering manifestations of experiences and outcomes.

\section{1 | Entering into moral sensitivity}

In this model, individuals develop a sense of moral sensitivity as they perceive the moral content of ordinary events and experiences. The development of moral sensitivity is followed by deliberation of moral 


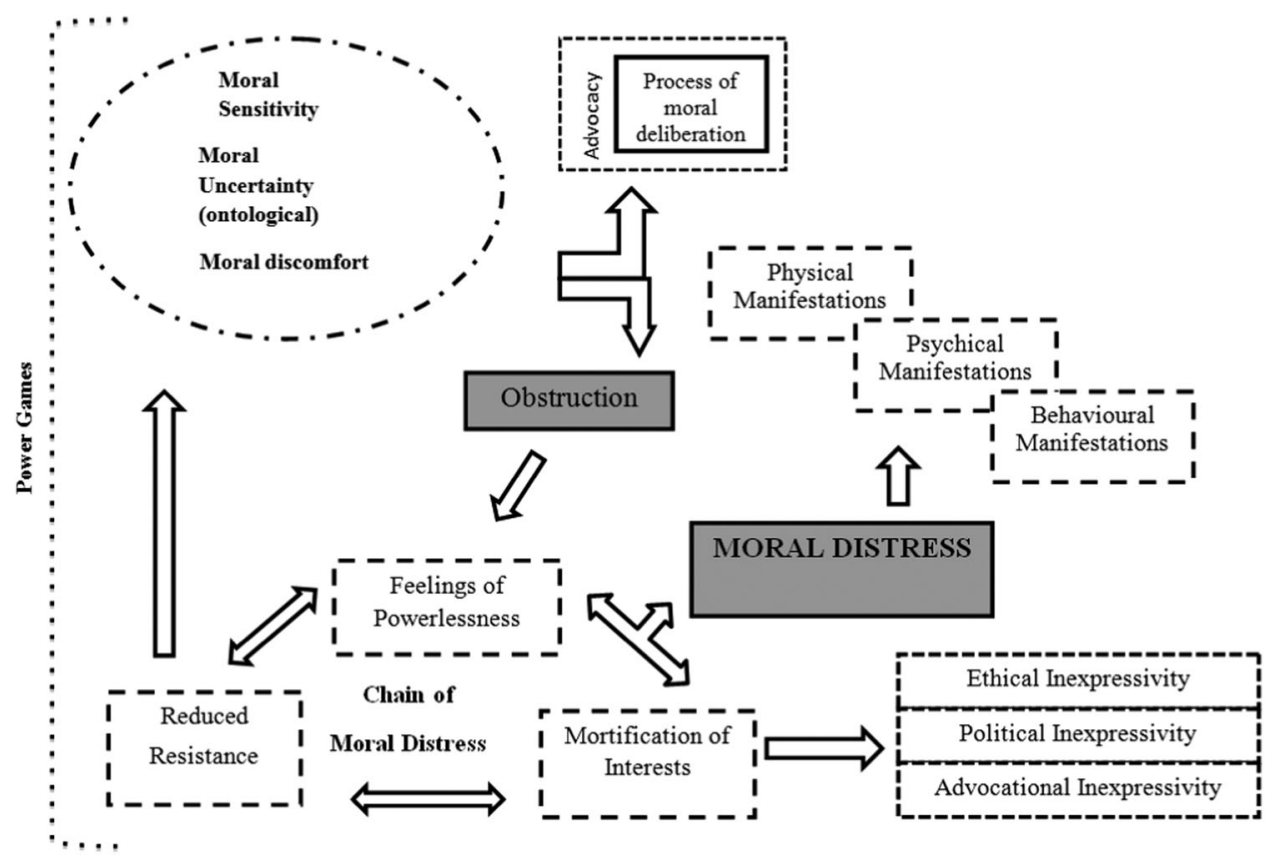

FIGURE 1 Conceptual model of moral distress. ${ }^{26}$ Request for reprint to be granted on March 30, 2019

problems on the continuum of moral strangeness and inquietude, where individuals grapple with feelings of unfamiliarity and restlessness around a moral situation, toward feelings of moral discomfort. The continuum provides a lens through which the individual may reflect and deliberate on the experience. This deliberation allows one to experience a heightened awareness of moral problems that may otherwise be suppressed. If the nurse identifies a moral problem, the individual may proceed with one of two paths; one offering a catalytic path of personal growth through moral development and the other offering the negative consequences of moral distress.

\subsection{1 | Path one}

The first major path evokes the process of moral deliberation in its entirety, involving deliberation of a moral problem, supposing available options, and making a decision or assuming a definitive position. The agency of advocacy emboldens the nurse to choose this path through confrontation with moral concern. Individuals taking path one are able to cope with moral challenges through an exploration of the problem and mobilization of resistance against moral distress. Outcomes are positive, with a focus on advocacy for self and others.

\subsection{2 | Path two}

The alternative major path is stagnation-in-uncertainty, called obstruction, and leads to the chain of moral distress when the process of moral deliberation is not fully experienced. Within this chain of moral distress, the individual may exit the chain at either of two points to reconsider the dilemma or continue indefinitely, creating a cycle. The primary point of exit occurs when the individual identifies moral distress and then opts for a second moral deliberation of the problem. The secondary point of exit is also by way of the identification of moral distress, but instead, the individual perceives the moral dimension of the situation and reverts to a position of moral strangeness. The final option is to continue in the chain of moral distress in a cyclical manner which results in stagnation. Stagnation ultimately alters the individual's professional ideals in favor of ongoing powerlessness. In some environments, stagnation and powerlessness may be perceived as a part of the expected professional culture and foster a sense of normality towards the existing barriers to advocacy. This sense of normality may increase passive and nonreactive behaviors toward moral problems.

\section{2 | Potential outcomes of moral distress}

The potential consequences of the nurse experiencing moral distress involve both proximal and distal ramifications. The most immediate consequence of moral distress, mortification of interests, is actually a part of the chain of moral distress. Mortification of interests is the suppression of one's desires, whereby the nurse suppresses his/her verbalization of internal conflict. Disengagement from an ethical conversation with unit leadership is an example of mortification of interests. The individual feels powerless to reconcile the moral conflict, in a disempowered environment. With an ongoing experience of moral distress, the individual may experience physical, psychological, and/or behavioral manifestations of internalized powerlessness.

\subsection{Application of the model to nurses caring for infants with neonatal abstinence syndrome}

The potential for a nurse to experience moral distress through the experience of caring for an infant with NAS is multi-faceted. Some 
nurses, most specifically nurse midwives, avoid moral distress by entering into the path of advocacy. ${ }^{38,39}$ However, much of the literature supports that many nurses struggle with moral conflict surrounding nursing care of infants with NAS.,8,12,13,40,41 Although the experience of moral distress in this professional circumstance is highly individual, some themes pointing to common internal conflicts are present in the literature.

The nurse's desire to provide optimal patient care is impeded by many variables including overwhelming comfort needs of the infant, unrealistic care expectations by some families, strained and tense interactions with families, and potential role conflict. However, the literature examining nurses' feelings toward caring for NAS infants consistently reveals that nurses are committed to the care and welfare of these infants. Nurses may struggle with two moral principles, beneficence and nonmaleficence while caring for infants with symptoms of NAS. ${ }^{7,8,13}$

Exemplifying beneficence toward the infant is illustrated by providing comfort, advocating for the infant's needs, and instructing other caregivers, including family, how to meet the infant's needs. The goal of beneficence may be challenged due to difficulty in treating symptoms of withdrawal and difficulty in coping with families who use substances. ${ }^{7,8,13}$ Treatment of the physical symptoms of withdrawal, such as inconsolable crying, vomiting, and diarrhea, and difficulty feeding can be difficult and overwhelming, as techniques commonly successful with non-NAS infants are less successful with NAS infants. Many nurses attribute these symptoms to the experience of pain in the infant. ${ }^{7,10}$ Stress and frustration are described as nurses are unable to meet the care and comfort needs of NAS infants and the needs of other infants also under their care in the same shift due to the time expenditure with NAS infants. ${ }^{7,8,11,12,41}$ Ultimately, the nurse may feel like he/she cannot meet any of her/his patient's needs.

Exemplifying nonmaleficence toward infants is illustrated by avoidance of harmful caregiving practices toward the infant and protecting the infant from harm by others. This may include discouraging others from stimulating or waking the infant and protecting the infant from a perceived threat to safety, such as a parent who uses substances. The goal of nonmaleficence may be challenged through the experience of verbal abuse and physical threats from some families of infants with NAS. Nurses fear for the safety of the infant upon discharge in the absence of a healthcare provider to protect the infant from harm..$^{7-9,13}$ If the nurse perceives that harm to the infant, in any circumstance, is a consequence of their inability to protect them, moral distress may be triggered.

In addition, the nurse may feel that actions necessary to exemplify nonmaleficence toward the infant simultaneously breach nonmaleficence to the mother. Mothers present the hope of mothering as a positive influence toward abstinence from substances. As the nurse protects the infant from potential harm by creating a barrier to the mother, the nurse may be simultaneously detracting from the mother's ability to engage in recovery. Deciding upon the superior priority is difficult, but even if the nurse is able to identify a superior priority, acting upon that priority may be prohibitive due to circumstance, environment, or power inequities within the healthcare system. ${ }^{26}$ Simultaneously, nurses are unable to communicate their feelings regarding the mother's violation of beneficence to the infant. $^{7,8,42}$ The nurses' perceptions of the inability to communicate such feelings stem from the mortification of interests as a part of the chain of moral distress. ${ }^{19,26}$

The potential consequences of the nurse experiencing moral distress involve both proximal and distal ramifications. The nurse may feel that the infant and mother's care needs are mutually exclusive and feel pressured to choose a priority patient, such as the infant with symptoms of NAS, their mother, or another infant under his/her care. ${ }^{5,8,12}$ The nurse may change his/her nursing practice as a part of mortification of interests, such as ambivalent nursing practice, decreased self-advocacy and/or depersonalization towards families of infants. ${ }^{19,24}$ Although the desire to leave bedside nursing care has been cited in other circumstances of moral distress, nurses overwhelmingly verbalize a desire to continue in their roles at the bedside in caring for infants with NAS symptoms. ${ }^{7,8,12}$ However, patient outcomes may deteriorate as a result of compromised care within an environment of perceived powerlessness and inability to meet professional ethical obligations.

\section{4 | THE CRESCENDO EFFECT}

Jameton ${ }^{16}$ used the term reactive distress to describe the painful feelings that remain following the acute circumstance of moral distress. The term has evolved into moral residue, utilizing the crescendo effect to describe the relationship between moral distress and moral residue. ${ }^{25,34}$ The moral residue that remains after an acute morally distressing event serves as a new baseline for moral distress. The level of residue continues to rise with repeated similar events, resulting in higher crescendos evoking stronger reactions as the previous emotions are pulled forward with each new experience. ${ }^{19,23-25,34}$ The primary concern with increasing crescendo magnitudes is the potential for some pivotal change in the nurse's practice or well-being. ${ }^{25}$ Although morally distressing events occur in low frequencies in nurses, the effects are significant when they do occur. ${ }^{19,25}$

\section{5 | TOWARD MORAL RESILIENCE}

The scholarship presented over the past three decades is overwhelmingly framed in a negative light whereby the nurse is presented as a victim of moral distress. Perhaps this negativity and powerlessness narrative is at least partially a self-fulfilling prophecy. ${ }^{22}$ Victor $\mathrm{Frankl}^{37}$ presented a framework of resiliency, whereby the identification of a positive purpose even in the direst of circumstances offers a way to move through the negativity of moral distress.

Although uncommon in the early literature on moral distress, the concept of moral resilience has re-emerged as an individual's capacity 
to cultivate skills and practices to further connect with and commit to his/her principal intentions when navigating ethically complex scenarios. ${ }^{22}$ This concept embraces the potential to diminish the negative effects of moral distress and promote the agency of advocacy. ${ }^{22,26,28,30,37,43}$ Moral resilience can be fostered through education on methods to support self-awareness and moral sensitivity, regulating negative thought and behavior patterns, nurturing courageous interventions and identifying meaning amidst adversity within an environment of organizational support. ${ }^{20,22,37,43}$ Within the context of caregiving for infants with symptoms of NAS and their families, moral resilience offers nurses the agency to identify sources of systemic disempowerment that may help to break the chain of moral distress and once again promote advocacy for the families whom they provide care.

\section{6 | CONCLUSION}

The literature is abundant with potential causes and descriptions of the various negative effects related to moral distress. The commonalities of causes and effects of moral distress depict the harmonies of the human spirit. It is far more common for people of all cultures and demographics to agree on the desire to help others, alleviate suffering, and avoid causing harm that is the potential to agree on the particular differences in the care needs of specific population bases.

Additional research is required on the developing concepts of the crescendo effect of moral distress and moral residue. The broad description of the crescendo effect is well-stated, but the impact of time and intensity upon moral residue is unknown. More work is needed to examine the interplay between moral distress and moral residue to understand the specific similarities and differences between these related concepts. Opportunities exist to build models that examine moral distress within organizations over time, examining the crescendo effect in a larger context. ${ }^{34}$ The continued development of the concept of moral resilience will come by way of better identifying early signs and symptoms of moral distress, opportunities to advocate for change and support, and reframing morally distressing situations into opportunities rather than restrictions. ${ }^{22,43}$

Nurses must find a way to reconcile the care of the infant with symptoms of NAS and their family that does not compromise nurses' moral integrity. The agency of moral resilience offers the most promising opportunity for the nurse to acknowledge this complex moral situation and henceforth identify interventions to lead and participate in endeavors that potentiate solutions and opportunities for growth. The challenge to meet the needs of this patient population is demanding and complex, yet the consequences of marginalizing the family as an indirect consequence of the nurse's moral distress and bias may last for generations and extend throughout society.

\section{ORCID}

Amber Welborn (iD) http://orcid.org/0000-0002-8905-7147

\section{REFERENCES}

1. Haight SC, Ko JY, Tong VT, Bohm MK, Callaghan WM. Opioid use disorder documented at delivery hospitalization - United States, 1999-2014. MMWR Morb Mortal Wkly Rep. 2018;67:845-849.

2. National Institute on Drug Abuse. (2015). 2016-2020 NIDA strategic plan: Advancing addiction medicine. Retrieved November 26, 2018, from. https://d14rmgtrwzf5a.cloudfront.net/sites/default/files/nida_ 2016strategicplan_032316.pdf

3. Hudak ML, Tan RC, Drugs TCO, Newborn TC, on F. A. Neonatal drug withdrawal. Pediatrics. 2012;129:e540-e560.

4. Winkelman TNA, Villapiano N, Kozhimannil KB, Davis MM, Patrick SW. Incidence and costs of neonatal abstinence syndrome among infants with medicaid: 2004-2014. Pediatrics. 2018;141(4):e20173520.

5. Fraser JA, Barnes M, Biggs HC, Kain VJ. Caring, chaos and the vulnerable family: experiences in caring for newborns of drugdependent parents. Int J Nurs Stud. 2007;44:1363-1370.

6. Jones HE, Fielder A. Neonatal abstinence syndrome: historical perspective, current focus, future directions. Prev Med. 2015;80:12-17.

7. Maguire D, Webb M, Passmore D, Cline G. NICU nurses' lived experience: caring for infants with neonatal abstinence syndrome. Advances in Neonatal Care. 2012;12:281-285.

8. Murphy-Oikonen J, Brownlee K, Montelpare W, Gerlach K. The experiences of NICU nurses in caring for infants with neonatal abstinence syndrome. Neonatal Netw. 2010;29:307-313.

9. Whittaker A, Williams N, Chandler A, Cunningham-Burley S, McGorm K, Mathews G. The burden of care: a focus group study of healthcare practitioners in Scotland talking about parental drug misuse. Health \& Social Care in the Community. 2016;24(5):e72-e80.

10. Nelson MM. NICU culture of care for infants with neonatal abstinence syndrome: a focused ethnography. Neonatal Netw. 2016;35(287):289-296.

11. Smith JG, Rogowski JA, Schoenauer KM, Lake ET. Infants in drug withdrawal: a national description of nurse workload, infant acuity, and parental needs. J Perinat Neonatal Nurs. 2018;32:72-79.

12. Romisher R, Hill D, Cong X. Neonatal abstinence syndrome: exploring nurses' attitudes, knowledge, and practice. Advances in Neonatal Care. 2018;18(2):E3-E11.

13. Shaw MR, Lederhos C, Haberman M, Howell D, Fleming S, Roll J. Nurses' perceptions of caring for childbearing women who misuse opioids. The American Journal of Maternal/Child Nursing. 2016;41:37-42.

14. Stengel $C$. The risk of being 'too honest': Drug use, stigma and pregnancy. Health Risk Soc. 2014;16:36-50.

15. Stone R. Pregnant women and substance use: fear, stigma, and barriers to care. Health \& Justice; Heidelberg. 2015;3:1-15.

16. Jameton A. Dilemmas of moral distress: moral responsibility and nursing practice. AWHONNS Clinical Issues in Perinatal and Women's Health Nursing. 1993;4:542-551.

17. Jameton A. Nursing practice: The ethical issues. Englewood Cliffs, N.J: Prentice-Hall; 1984.

18. McCarthy J, Gastmans C. Moral distress: a review of the argumentbased nursing ethics literature. Nurs Ethics. 2015;22:131-152.

19. Oh Y, Gastmans C. Moral distress experienced by nurses: a quantitative literature review. Nurs Ethics. 2015;22:15-31.

20. Rodney PA. What we know about moral distress. American Journal of Nursing. 2017;117:S7-S10.

21. Burston AS, Tuckett AG. Moral distress in nursing: contributing factors, outcomes, and interventions. Nurs Ethics. 2013;20:312-324.

22. Rushton $\mathrm{CH}$, Schoonover-Shoffner K, Kennedy MS. Executive summary: transforming moral distress into moral resilience in nursing. AJN, American Journal of Nursing. 2017;117(2):52-56. 
23. Cavaliere TA, Daly B, Dowling D, Montgomery K. Moral distress in neonatal intensive care unit RNs. Advances in Neonatal Care. 2010;10:145-156.

24. Trautmann J. Moral distress: recognition, diagnosis, and treatment. J Infus Nurs. 2015;38:285-289.

25. Epstein E, Delgado S. Understanding and addressing moral distress. Online J Issues Nurs. 2010;15(3):1-1.

26. Barlem E, Ramos F. Constructing a theoretical model of moral distress. Nurs Ethics. 2015;22:608-615.

27. Dudzinski DM. Navigating moral distress using the moral distress map. Journal of Medical Ethics; London. 2016;42:321-324.

28. McCarthy J, Deady R. Moral distress reconsidered. Nurs Ethics. 2008; 15:254-262.

29. Thomas TA, McCullough LB. A philosophical taxonomy of ethically significant moral distress. Journal of Medicine \& Philosophy. 2015;40:102-120.

30. Corley MC. Nurse moral distress: a proposed theory and research agenda. Nurs Ethics. 2002;9(6):636-650.

31. Sannino $P$, Giannì ML, Re LG, Lusignani M. Moral distress in the neonatal intensive care unit: an Italian study. J Perinatol. 2015;35:214-217.

32. Schaefer R, Zoboli ELCP, Vieira M. Identification of risk factors for moral distress in nurses: basis for the development of a new assessment tool. Nurs Inquiry. 2016;23:346-357.

33. Coombs MA. Concerns about care and communication are key causes of moral distress in intensive care staff. Aust Crit Care. 2017;30:107-108.

34. Epstein EG, Hamric AB. Moral distress, moral residue, and the crescendo effect. J Clin Ethics. 2009;20:330-342.

35. Barlem ELD, Lunardi VL, Lunardi GL, Tomaschewski-Barlem JG, Silveira RSda. Moral distress in everyday nursing: Hidden traces of power and resistance. Rev Lat Am Enfermagem. 2013;21:293-299.

36. Wilkinson JM. Moral distress in nursing practice: experience and effect. Nurs Forum. 1987;23:16-29.

37. Frankl VE. Man's search for meaning: an introduction to logotherapy. New York: Pocket Books; 1963.

38. Fonti S, Davis D, Ferguson S. The attitudes of healthcare professionals towards women using illicit substances in pregnancy: a crosssectional study. Women and Birth. 2016;29:330-335.
39. Jenkins L. A survey of midwives' attitudes towards illicit drug use in pregnancy. The Royal College of Midwives. 2013;11(1):10-15.

40. Fraser MR. Bringing it all together: Effective maternal and child health practice as a means to improve public health. Matern Child Health J. 2013;17:767-775.

41. Sweigart E. Compassion fatigue, burnout, and neonatal abstinence syndrome. Neonatal Netw. 2017;36:7-11.

42. Raeside L. Specialist nursing. Attitudes of staff towards mothers affected by substance abuse. British Journal of Nursing. 2003;12(5):302-310.

43. Rushton C. Cultivating moral resilience. LWW. 2017;117(2):S11-S15.

\section{AUTHOR BIOGRAPHY}

Amber Welborn has a Masters in Nursing Education and is currently a PhD student, having recently defended her study proposal. Her research interest relates to healthcare for women and children as vulnerable populations, as well as qualitative methodologies including phenomenology and discourse analysis. Her clinical expertise is in maternal-child, high-risk neonatal, and community health. She is also an experienced nurse educator specializing in maternal-child nursing care with undergraduate students.

How to cite this article: Welborn A. Moral distress of nurses surrounding neonatal abstinence syndrome: Application of a theoretical framework. Nurs Forum. 2019;54:499-504.

https://doi.org/10.1111/nuf.12362 